\title{
Direct conversion of theophylline to 3-methylxanthine by metabolically engineered $E$. coli
}

\section{Open Accest}

\author{
Khalid H. R. Algharrawi ${ }^{1,4}$, Ryan M. Summers ${ }^{2}$, Sridhar Gopishetty ${ }^{3}$ and Mani Subramanian ${ }^{*}$
}

\begin{abstract}
Background: Methylxanthines are natural and synthetic compounds found in many foods, drinks, pharmaceuticals, and cosmetics. Aside from caffeine, production of many methylxanthines is currently performed by chemical synthesis. This process utilizes many chemicals, multiple reactions, and different reaction conditions, making it complicated, environmentally dissatisfactory, and expensive, especially for monomethylxanthines and paraxanthine. A microbial platform could provide an economical, environmentally friendly approach to produce these chemicals in large quantities. The recently discovered genes in our laboratory from Pseudomonas putida, ndmA, ndmB, and ndmD, provide an excellent starting point for precisely engineering Escherichia coli with various gene combinations to produce specific high-value paraxanthine and 1-, 3-, and 7-methylxanthines from any of the economical feedstocks including caffeine, theobromine or theophylline. Here, we show the first example of direct conversion of theophylline to 3-methylxanthine by a metabolically engineered strain of E. coli.

Results: Here we report the construction of E. coli strains with $n d m A$ and $n d m D$, capable of producing 3-methylxanthine from exogenously fed theophylline. The strains were engineered with various dosages of the $n d m A$ and $n d m D$ genes, screened, and the best strain was selected for large-scale conversion of theophylline to 3-methylxanthine. Strain pDdA grown in super broth was the most efficient strain; $15 \mathrm{mg} / \mathrm{mL}$ cells produced $135 \mathrm{mg} / \mathrm{L}$ (0.81 mM) 3-methylxanthine from $1 \mathrm{mM}$ theophylline. An additional $21.6 \mathrm{mg} / \mathrm{L}(0.13 \mathrm{mM})$ 1-methylxanthine were also produced, attributed to slight activity of $\mathrm{NdmA}$ at the $\mathrm{N}_{3}$-position of theophylline. The 1- and 3-methylxanthine products were separated by preparative chromatography with less than $5 \%$ loss during purification and were identical to commercially available standards. Purity of the isolated 3-methylxanthine was comparable to a commercially available standard, with no contaminant peaks as observed by liquid chromatography-mass spectrophotometry or nuclear magnetic resonance.
\end{abstract}

Conclusions: We were able to biologically produce and separate $100 \mathrm{mg}$ of highly pure 3-methylxanthine from theophylline (1,3-dimethylxanthine). The N-demethylation reaction was catalyzed by E. coli engineered with $\mathrm{N}$-demethylase genes, $n d m A$ and $n d m D$. This microbial conversion represents a first step to develop a new biological platform for the production of methylxanthines from economical feedstocks such as caffeine, theobromine, and theophylline.

Keywords: 3-methylxanthine, 1-methylxanthine, Theophylline, E. coli, Biocatalyst, N-demethylation, Preparative chromatography, Metabolic engineering

\section{Background}

Xanthine is a ubiquitous naturally occurring purine base. Other common naturally occurring xanthine derivatives

\footnotetext{
*Correspondence: mani-subramanian@uiowa.edu

1 Department of Chemical and Biochemical Engineering, The University

of lowa, Coralville, IA 52241, USA

Full list of author information is available at the end of the article
}

include caffeine (1,3,7-trimethylxanthine), theobromine (3,7-dimethylxanthine), and theophylline (1,3-dimethylxanthine, TP), which are found in many foods, drinks, and pharmaceuticals [1-3]. Paraxanthine (1,7-dimethylxanthine) and 1-, 3-, and 7-methylxanthines are also naturally occurring xanthine derivatives, but are transient metabolites found at very low levels $[1,2,4]$. Several 
xanthine derivatives have also been synthesized chemically for use in the medical industry [5]. These compounds, natural and synthetic, have been shown to have various biomedical effects, with targets including adenosine receptors $[6,7]$, phosphodiesterases $[8,9]$, calcium release channels [10-13], and $\mathrm{GABA}_{\mathrm{A}}$ receptors [13, 14].

For example, 3-methylxanthine (3MX) has been assessed as an adenosine antagonist [6] and produces the same maximal relaxation of guinea pig tracheal muscle as does TP [15]. Given that 3MX is a metabolite of TP in humans [16], TP itself may be a prodrug; thus there is an interest in directly testing $3 \mathrm{MX}$ as well. $3 \mathrm{MX}$ and TP are also used to examine conformational heterogeneity in RNA aptamers and riboswitches [17, 18]. 1-methylxanthine (1MX) is an essential human urinary metabolite of caffeine and TP [19-22] and exhibits similar activities to other naturally occurring methylxanthines. Unlike caffeine, TP, and theobromine, 3MX and $1 \mathrm{MX}$ do not occur naturally at high levels in plants. Instead, $3 \mathrm{MX}$ and $1 \mathrm{MX}$ are currently produced only by chemical methods, which are difficult due to the challenge of achieving selective alkylation of each of the nitrogen atoms [23-26].

Many purine alkaloids are traditionally produced via Traube synthesis, which uses the cyclization of 4,5-diaminopyrimidines with formic acid, dithioformic acid, or other carboxylic acids [27, 28]. Imidazoles are also used for the production of purines [29]. Zavialov et al. developed a practical method describing the synthesis of 1 - and 1,3- substituted xanthines by reacting an imidazole precursor with carbamates in the presence of suitable base [30]. The reaction was carried out under inert conditions using solvents such as tetrahydrofuran, bis(2-methoxyethyl) ether, and toluene. About seven steps of synthesis were needed to get the targeted methylxanthine. Allwood et al. developed a highly efficient synthesis route to $N$-functionalized derivatives of xanthine by orthogonal safety-catch protection strategy using cyclocondensation of aminoimidazole with methyl2-phenylthioethyl carbamates [31]. Liu et al. synthesized novel substituted xanthines by 46 routes [32]. In one of the routes, xanthine analogs containing substituents at the $N_{1}, N_{3}$, and $N_{7}$ atoms were produced by treating 1,3-dialkyl-5,6-diaminouracils with triethylorthoformate. Traditionally, synthetic methods for the production of purine alkaloids utilize many undesirable chemicals, solvents, and harsh reaction conditions, and result in multiple reactions with undesired products; therefore, it is complicated and expensive (Fig. 1a). For synthesis of specific alkylxanthines, such as $3 \mathrm{MX}$, additional deprotection steps are needed and the overall yield from starting material such as an imidazole precursor is highly variable, i.e., 65-90\%. However, the exact yield of each specific methylxanthine is not clear. At each step of the reaction, the intermediate needs to be purified before the next step. Three different solvents reportedly give different yields [30].

Caffeine and related methylxanthines are toxic to most bacteria and invertebrates [33, 34]. However, some bacteria, most of which are Pseudomonads, have evolved the ability to metabolize caffeine [35-42]. The bacterial strain Pseudomonas putida CBB5 degrades caffeine via sequential $N$-demethylation to theobromine (3,7-dimethylxanthine), 7-methylxanthine, and ultimately xanthine [38]. CBB5 can also $N$-demethylate TP to $1 \mathrm{MX}$ and $3 \mathrm{MX}$, which are further $N$-demethylated to xanthine. This is the first bacterial strain reported to grow on and metabolize TP [38]. These same pathways for caffeine and TP metabolism have also been characterized genetically in Pseudomonas sp. CES [39].

The enzyme NdmA catalyzes the $N_{1}$-demethylation of $\mathrm{TP}$ to 3MX. In addition, NdmA also converts caffeine to theobromine [43]. This enzyme is a Rieske (2Fe-2S) non-heme iron monooxygenase that requires a partner reductase, $\mathrm{NdmD}$, to transfer electrons from $\mathrm{NADH}$. The reaction requires one molecule of $\mathrm{O}_{2}$ per methyl group removed, resulting in the production of formaldehyde and water. We previously showed that the $n d m A$ and $n d m D$ genes are expressed partly in soluble form in Escherichia coli [43], and that a strain expressing both genes can be used to convert caffeine to theobromine [44].

Our broader interest is to generate a new, common platform for biocatalytic production of several high value methylxanthines via metabolically engineered $E$. coli (Fig. 1b) from cheaper feedstocks such as caffeine, TP and theobromine (see Additional file 1: Table S1 for relative value of each compound). There is a high-value differential between TP and desired product, 3MX (Fig. 1b). Our initial focus has been to produce $3 \mathrm{MX}$ from TP using $E$. coli engineered with $n d m A$ and $n d m D$. Biocatalytically-produced $3 \mathrm{MX}$, besides reagent market as well as potential pharmaceutical effects [6], has commercial application as a nutraceutical (unpublished, personal communication between senior author and two different nutraceutical companies). There are several suppliers of synthetic 3MX as reagents worldwide [45], but no current suppliers of 3MX produced through biocatalytic means. The preferred substrate of the NdmA enzyme is $\mathrm{TP}$, with a $\mathrm{k}_{\mathrm{cat}} / \mathrm{K}_{\mathrm{M}}$ ratio for TP nearly double that of caffeine [43]. The present work is the first report on the biocatalytic production of $3 \mathrm{MX}$. The genes $n d m A$ and $n d m D$ were introduced into $E$. coli at different gene dosages, and the resultant strains were screened for 3MX production. The optimum strain with the highest $3 \mathrm{MX}$ production was chosen for further study, including small-scale production of 3MX to dispatch to clients. NdmA produced 
a<smiles>[R]NC(=O)O[R][H]</smiles>

1-PMB-4-Amino5-ethoxycarbonylimidazole

Alkyl Carbamate<smiles>[R]N=C(Nc1ncn(N(C)C)c1C(=O)OCC)O[M]</smiles>

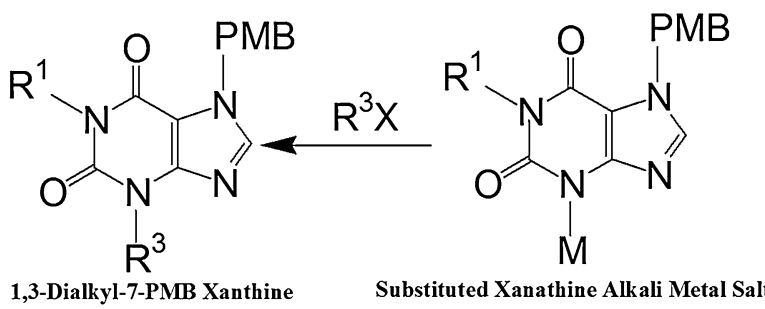

$\mathrm{PMB}=\mathrm{p}-$ Methoxybenzyl; $M=\mathrm{Li}, \mathrm{Na} ; \mathrm{R}^{1}=\mathrm{R}^{3}=\mathrm{CH}_{3}$ or $\mathrm{H}$

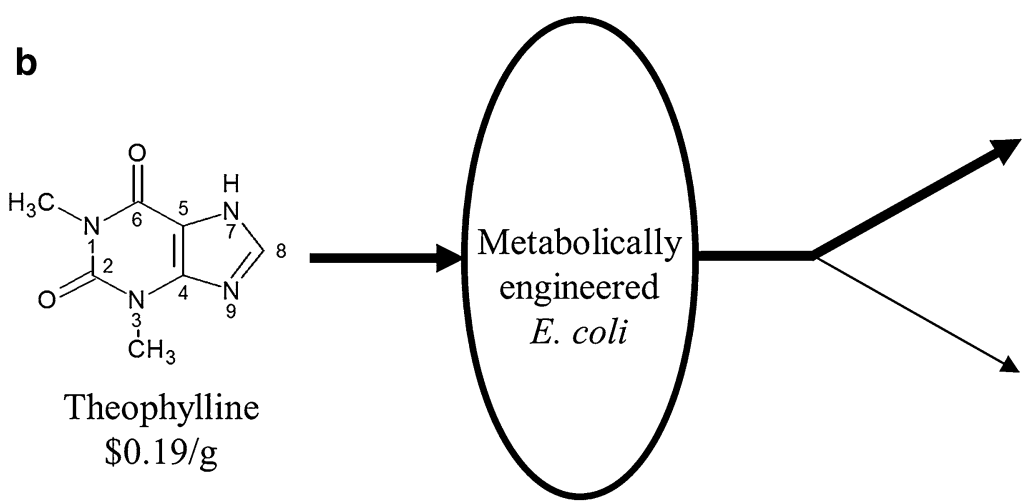<smiles>Cn1c(=O)[nH]c(=O)c2[nH]cnc21</smiles>

3-methylxanthine (major product)<smiles>[134Os]</smiles><smiles>Cn1c(=O)[nH]c2nc[nH]c2c1=O</smiles>

1-methylxanthine (minor product)

$\$ 845.00 / \mathrm{g}$

Fig. 1 Methylxanthine production schemes. a Example of generalized synthetic methods adapted from [30]. b Production of 3MX (major product) and $1 \mathrm{MX}$ (minor product) from TP by metabolically engineered $E$. coli containing the $n d m A$ and $n d m D$ genes. Prices per gram given below the compounds are based on the Sigma Aldrich Catalog for the highest lot available (Additional file 1: Table S1)

1MX as a minor product as a result of non-specific $\mathrm{N}$-demethylation at the $N_{3}$-position. $1 \mathrm{MX}$ was not fully characterized since this is not the best method to produce this fine chemical. The biocatalytic approach used here operates at ambient temperature and pressure and is environmentally friendly. In contrast, chemical synthesis of methylxanthines uses several chemicals, multiple reactions, and non-ambient reaction conditions (Fig. 1a).

\section{Results and discussion} Initial screening of growth and $3 \mathrm{MX}$ production by metabolically engineered $E$. coli

All plasmids and strains used in this work are listed in Table 1, and plasmid maps are provided in Additional file 1: Figure S1. We first tested conversion of TP to 3MX using a strain of $E$. coli that contained plasmid pAD1 [23]. Resting cells $\left(\mathrm{OD}_{600}=2.5\right)$ converted approximately 
Table 1 Plasmids and strains used in this study

\begin{tabular}{|c|c|c|}
\hline Name & Characteristics & Source \\
\hline \multicolumn{3}{|l|}{ Plasmids } \\
\hline pAD1 & Amp ${ }^{R}, T 7$ promoter, $n d m A, n d m D$, rbsAD1, F1 origin & {$[44]$} \\
\hline pET28-His-ndmD & $\mathrm{Kan}^{\mathrm{R}}, \mathrm{T} 7$ promoter, $n d m D, \mathrm{~F} 1$ origin & [43] \\
\hline pACYCDuet-1 & Expression vector, $\mathrm{Cm}^{\mathrm{R}}, 2 \mathrm{T7}$ promoters, p15A origin & Novagen \\
\hline$d A$ & pACYCDuet- 1 with one copy of $n d m A$ & This study \\
\hline $\mathrm{dAO}$ & pACYCDuet-1 with one copy of $n d m A$ and a second MCS & This study \\
\hline dAA & pACYCDuet- 1 with two copies of $n d m A$ & This study \\
\hline $\mathrm{dD0}$ & pACYCDuet-1 with one copy of $n d m D$ and a second MCS & This study \\
\hline $\mathrm{dDD}$ & pACYCDuet- 1 with two copies of $n d m D$ & This study \\
\hline $\mathrm{dDA}$ & pACYCDuet- 1 with one copy of $n d m D$ and on copy of $n d m A$ & This study \\
\hline \multicolumn{3}{|l|}{ E. colistrains } \\
\hline E. coli BL21(DE3) & $\mathrm{F}^{-}$ompThsdS $\mathrm{B}_{\mathrm{B}}\left(\mathrm{r}_{\mathrm{B}}^{-} \mathrm{m}_{\mathrm{B}}^{-}\right) \mathrm{gal} \mathrm{dcm}(\mathrm{DE} 3)$ & Invitrogen \\
\hline E. coli pAD1 ${ }^{\mathrm{a}}$ & BL21(DE3) pAD1 & {$[44]$} \\
\hline E. coli pAD1dDD & BL21(DE3) pAD1 dDD & This study \\
\hline E. coli pAD1dDA & BL21(DE3) pAD1 dDA & This study \\
\hline E. coli pAD1dAA & BL21(DE3) pAD1 dAA & This study \\
\hline E. coli dDA & BL21(DE3) dDA & This study \\
\hline E. coli pHisD & BL21(DE3) pET28-His-ndmD & {$[43]$} \\
\hline E. coli pDdAA & BL21(DE3) pET28-His-ndmD dAA & This study \\
\hline E. coli pDdA & BL21(DE3) pET28-His-ndmD dA & This study \\
\hline
\end{tabular}

a Strain $\mathrm{pAD} 1$ was originally named $E$. coli strain RMS1 in a previous publication [44]

$0.3 \mathrm{mM}$ TP to $3 \mathrm{MX}$ over $1 \mathrm{~h}$, after which the reaction essentially stopped (Fig. 2). In order to increase activity, plasmids $\mathrm{dAA}, \mathrm{dDD}$, and $\mathrm{dDA}$ were added to the strain carrying pAD1, resulting in three new strains. These

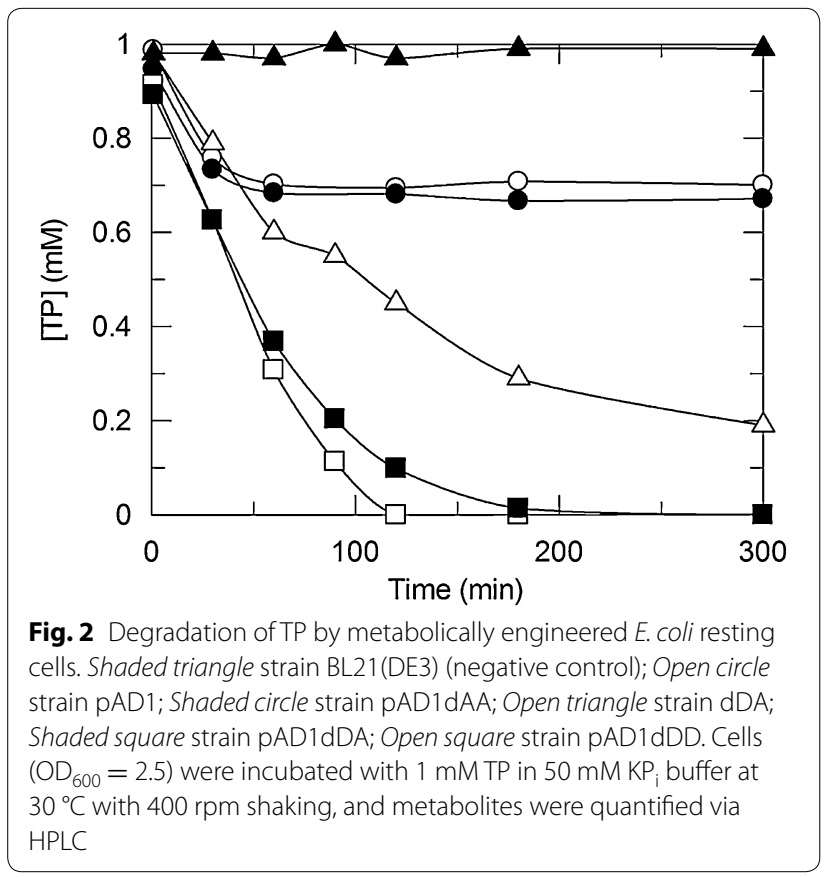

new strains allowed us to test the effect of different levels of $n d m A$ and $n d m D$ copy numbers on $3 \mathrm{MX}$ production (see Additional file 1: Table S2 for approximate gene copy numbers of each strain). Addition of $n d m A$ only (strain pAD1dAA) had very little effect on activity (Fig. 2). Increasing the copy number of both genes (strain pAD1dDA) greatly increased the activity over strain pAD1dAA, with nearly complete conversion in $3 \mathrm{~h}$. However, increasing the $n d m D$ gene copy number only (strain pAD1dDD) resulted in complete conversion of TP within $2 \mathrm{~h}$ (Fig. 2). Strain pAD1dDD, which contained the lowest $n d m A$ copy number, exhibited a slightly higher activity than did strain pAD1dDA, suggesting that plasmid pAD1 provided a sufficient $n d m A$ gene dosage. These results also indicated that the reaction was limited by the amount of soluble $\mathrm{NdmD}$ produced inside the cells, since the activity increased with increasing $n d m D$ copy number.

In the case of plasmid pAD1, the $n d m D$ gene is separated from the T7 promoter by approximately $1.1 \mathrm{~kb}$ of sequence containing the $n d m A$ ribosomal binding site and gene, followed by a short synthetic ribosomal binding site of unknown strength just before the $n d m D$ gene (Additional file 1: Figure S1). SDS-PAGE of strain pAD1 (Additional file 1: Figure S2) showed a strong band of soluble NdmA, but very little NdmD (soluble or insoluble). In contrast, strain pAD1dDD had very strong soluble 
and insoluble NdmD bands. Based on activity and electrophoretic analysis, plasmid pAD1 clearly did not produce sufficient soluble intracellular $\mathrm{NdmD}$. This was confirmed using resting cells $\left(\mathrm{OD}_{600}=2.5\right)$ of an E. coli strain containing only plasmid $\mathrm{dDA}$, which consumed $0.8 \mathrm{mM}$ TP over $300 \mathrm{~min}$ (Fig. 2). Plasmid dDA is based on the pACYCDuet-1 backbone, giving a plasmid (and gene) copy number approximately fourfold lower than that of pAD1. In spite of the lower overall gene dosage, activity was much higher in strain $\mathrm{dDA}$ than in strains pAD1 and pAD1dAA. Methods to increase expression of $n d m D$ from plasmid pAD1 only could involve using a known strong ribosomal binding site and/or a second T7 promoter between $n d m A$ and $n d m D$.

In order to increase intracellular levels of $\mathrm{NdmD}$, a plasmid containing the $n d m D$ gene placed immediately downstream of the T7 promoter and ribosomal binding site in pET28a $(+)$ [43] was used. Compatible plasmids containing one or two copies of $n d m A$ (plasmids dA and dAA, respectively) were then added to a strain of $E$. coli harboring pET28-His-ndmD. This resulted in strains with a low (pDdA) or medium (pDdAA) $n d m A$ gene dosage, based on estimated copy number and number of genes in each plasmid. The activity and protein expression levels of these two strains were then compared with strain pAD1dDD, which had the highest $n d m A$ dosage of the three (Additional file 1: Table S2). Strains pDdA, pDdAA, and pAD1dDD grew to a similar $\mathrm{OD}_{600}$ in $100 \mathrm{~mL}$ Luria-Bertani broth (LB) (Additional file 1: Table S3) when gene expression was induced as described in the "Methods" section. SDS-PAGE revealed that soluble (active) protein expression is about the same for NdmA and NdmD among the three strains (Additional file 1: Figure S2). Each wet cell paste was used to test the conversion of TP to 3MX by resuspending in $\mathrm{KP}_{\mathrm{i}}$ buffer to a final cell concentration of $30 \mathrm{mg} / \mathrm{mL}$ and initial TP concentration of $4 \mathrm{mM}$. After $90 \mathrm{~min}$ of the reaction time, TP was reduced 56,51 , and $43 \%$ by suspensions of pDdA, pDdAA, and pAD1dDD, respectively. Approximately 84,82 , and $81 \%$ of the consumed TP was converted to $3 \mathrm{MX}$ in strains $\mathrm{pDdA}, \mathrm{pDdAA}$, and $\mathrm{pAD} 1 \mathrm{dDD}$, respectively, with the remaining TP forming $1 \mathrm{MX}$ (Additional file 1: Table S3). Based on these results, strain pDdA was chosen for further studies due to the highest yield of $3 \mathrm{MX}$ from TP. Clearly, the additional gene dosage of $n d m A$ (pDdAA) did not improve 3MX yield, relative to single gene dose (pDdA). Therefore, the activity of the cells was proven to be independent of the $n d m A$ gene dosage and highly dependent on the $n d m D$ gene dosage and expression in each $E$. coli strain.

\section{Comparison of growth media}

The effect of culture medium on cell growth and activity was also measured by growing strain pDdA in
Luria-Bertani Lennox (LB) and super broth (SB) media. SB produced approximately $50 \%$ more cells than did LB (Additional file 1: Table S4). Cells were resuspended to $15 \mathrm{mg} / \mathrm{mL}$, and the initial TP concentration in activity assays was lowered to $1 \mathrm{mM}$ in order to achieve complete conversion, which would facilitate downstream purification and product recovery. TP was completely consumed in SB-grown cells within 90 min (Fig. 3). After 2 h, nearly all of the TP was consumed in both reactions (Additional file 1: Table S4). 3MX yield from TP was $82-83 \%$, with an additional $12-13 \%$ being $1 \mathrm{MX}$. Because the cells are capable of performing both $N_{1}$ - and $N_{3}$-demethylations on both TP and also 1- and 3MX, some small amount of xanthine was also formed from the monomethylxanthine products. These results demonstrate that the media composition had no significant effect on product ratio. Given the complete conversion of TP achieved in shorter time and $50 \%$ more biocatalyst harvested from $\mathrm{SB}$, this medium was chosen for the production of 3MX to supply clients.

Although yield of $3 \mathrm{MX}$ is high, minor production of $1 \mathrm{MX}$ decreases the overall yield of 3MX. The slight $\mathrm{N}_{3}$-demethylation of TP by $\mathrm{NdmA}$ to form $1 \mathrm{MX}$ is surprising and in contrast with our previous findings that NdmA is highly specific for the $N_{1}$ methyl group of caffeine and TP [43]. We therefore tested the activity of strain pDdA on caffeine and observed a slight (<2\%) $N_{3}$-demethylation activity to form paraxanthine (1,7-dimethylxanthine, data not shown). The enzyme in the previously reported work was expressed in E. coli BL21(DE3) with a C-terminal hexahistidine $\left(\mathrm{His}_{6}\right)$ tag for facile purification and assayed in vitro,

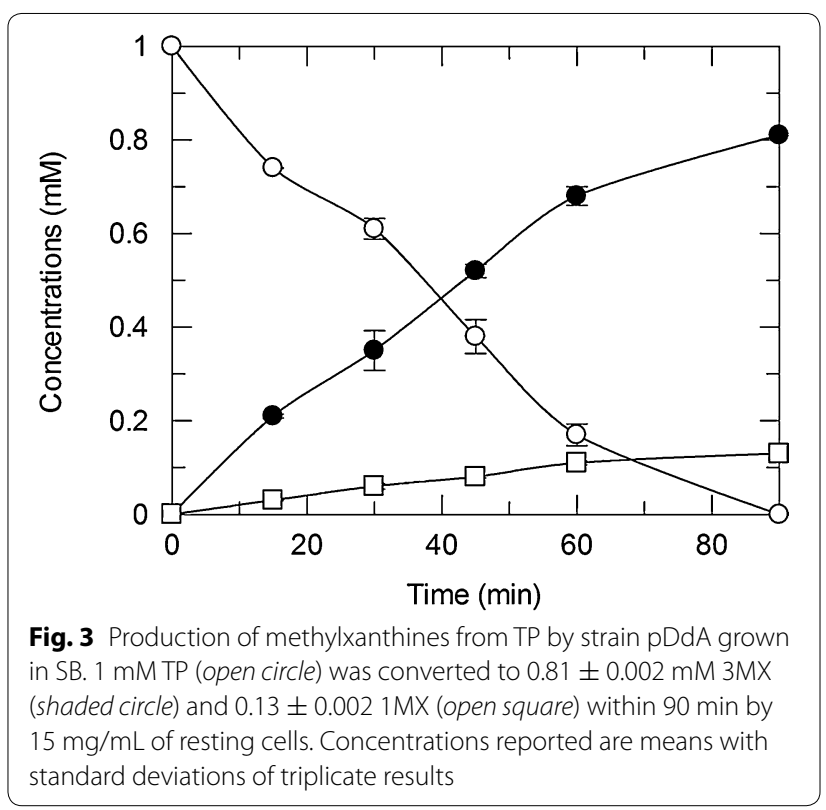


and produced only 3MX from TP. $1 \mathrm{MX}$ was shown to be produced from TP by the highly-specific $N_{3}$-demethylase NdmB-His. The present study utilizes NdmA expressed in the same microbial chassis without the $\mathrm{His}_{6}$ tag, and the reaction is carried out in vivo. It is unclear whether performing the reaction in vivo, elimination of the $\mathrm{His}_{6}$ tag from NdmA, enzyme expression level, and/or enzyme solubility [46] are involved in the change in site specificity. In our in vitro studies, the minimum amount of enzyme was used in order to determine the kinetics [43], and the paraxanthine and 1MX products may have been below the detection limit. However, the reduction in enzyme expression level (comparing strains pAD1 and dDA vs. strain pDdA) in this work did not result in a lower ration of products. Clearly, an in vitro approach would not be economical, as it would require addition of external NADH. It should be noted, however, that addition of a $\mathrm{His}_{6}$ tag has been implicated in changing substrate specificity of the thioesterase I in E. coli due to a slight change in active site geometry [47]. The reason for the discrepancy between NdmA and NdmA-His is currently under investigation. The original strain of $P$. putida CBB5 produced approximately twice as much $3 M X$ as $1 \mathrm{MX}$ [38], however, the 1MX production in this strain, besides slight specificity of $\mathrm{NdmA}$ at $N_{3}$-position, can mostly be attributed to $\mathrm{NdmB}$ [43]. Future work to reduce the $N_{3}$-demethylation activity of $\mathrm{NdmA}$ in vivo when expressed in E. coli should create a more efficient process for production of $3 \mathrm{MX}$, while simultaneously simplifying downstream recovery of $3 \mathrm{MX}$.

\section{Larger scale reaction, preparative chromatography, and purification of $3 \mathrm{MX}$}

The reaction conditions for conversion of TP to 3MX were optimized by evaluating different concentrations of cells $(5,10,15,30$, and $60 \mathrm{mg}$ wet cells $/ \mathrm{mL})$ and initial substrate concentration ( 1,2 , and $4 \mathrm{mM} \mathrm{TP})$. It is clear from the data presented in Fig. 4 that a reaction containing $1 \mathrm{mM}$ TP and $15 \mathrm{mg} / \mathrm{mL}$ resting cells provides linear conversion of TP to $3 \mathrm{MX}$. At these reaction conditions, the product concentration and reaction volume suited the prep high pressure liquid chromatography (HPLC) column for complete product recovery.

Production of 3MX was scaled up by growing the pDdA strain in SB media in four 2.8 L Fernbach flasks, resulting in a total yield of $20 \mathrm{~g}$ wet cells. The cell yield was sufficient to perform a $1.3 \mathrm{~L}$ reaction with an initial TP concentration of $1 \mathrm{mM}$ at $15 \mathrm{mg} / \mathrm{mL}$ resting cell suspension. Initial analysis by HPLC showed complete consumption of TP after $2 \mathrm{~h}$ of reaction time with formation of 0.81 and $0.13 \mathrm{mM} 3 \mathrm{MX}$ and $1 \mathrm{MX}$, respectively. The products were separated by preparative chromatography (Additional file 1: Figure S3). Resolution of 3MX (retention time of $116 \mathrm{~min}$ ) and $1 \mathrm{MX}$ (retention time of $136 \mathrm{~min}$ ) was sufficient to collect each of the two products separately. The two products were crystallized through evaporation and freeze-drying, resulting in $106 \mathrm{mg} 3 \mathrm{MX}$ and a minor amount of $1 \mathrm{MX}$. Because the very small amount of $1 \mathrm{MX}$ produced could not be collected from the walls of the freeze dryer tray, 1MX was not further characterized. We are attempting to produce $1 \mathrm{MX}$ from TP via a metabolically engineered $E$. coli host containing $n d m B$ and $n d m D$. The NdmB enzyme has been shown to be highly specific for $N_{3}$-demethylation [43], and a purified $\mathrm{NdmB}-\mathrm{His}_{6}$ produced only $1 \mathrm{MX}$ in vitro.

The theoretical amount of $3 \mathrm{MX}$ produced in the reaction was $175 \mathrm{mg}$ ( $\sim 81 \%$ mole to mole conversion from $\mathrm{TP}$ ); however $36 \%$ of the post-reaction mixture was used to optimize the preparative chromatographic separation. Therefore, a total of $111 \mathrm{mg} 3 \mathrm{MX}$ (64\% of the post-reaction mixture) was loaded onto the column for purification and recovery. The resulting $106 \mathrm{mg}$ pure $3 \mathrm{MX}$ indicates very little loss during separation with a purification yield of $95.5 \%$ after optimization of separation in the prep column. Improving the selectivity of $\mathrm{NdmA}$ so that it only produces $3 \mathrm{MX}$ from TP would further increase the yield.

The reaction conditions described here could produce $135 \mathrm{mg} / \mathrm{L} 3 \mathrm{MX}$. To our knowledge, this is the first report describing the non-transient microbial production of $3 \mathrm{MX}$. Until now, all microbial production of 3MX has been as an intermediate in the caffeine and TP catabolic pathways $[38,48]$. Therefore, there are no values in the literature with which to compare this yield. However, there was adequate amount for further analytical work and supply of samples to our clients.

Because the $n d m$ genes have only recently been discovered [43, 46], previous attempts to produce methylxanthines through a biocatalytic route have focused primarily on metabolism and enzymology studies for conversion of caffeine to theobromine. Research has shown that addition of certain divalent metal ions, such as $\mathrm{Co}^{2+}, \mathrm{Ni}^{2+}, \mathrm{Cu}^{2+}$, and $\mathrm{Zn}^{2+}$ have a strong inhibitory effect on degradation of theobromine accumulated from caffeine in whole cells of $P$. putida $[49,50]$. However, there are no known specific inhibitors to stop the reaction at the desired, high-value methylxanthines such as paraxanthine and 1-, 3-, and 7-methylxanthine. Also, this approach would not be optimal for methylxanthine production, as the wild type P. putida strains (CBB5 and others) have lower growth rates and cannot produce the same amount of enzyme (hence, catalytic activity) as can E. coli expressing the recombinant $n d m$ genes. Jin et al. [51] cloned genes from the caffeine biosynthetic pathway 

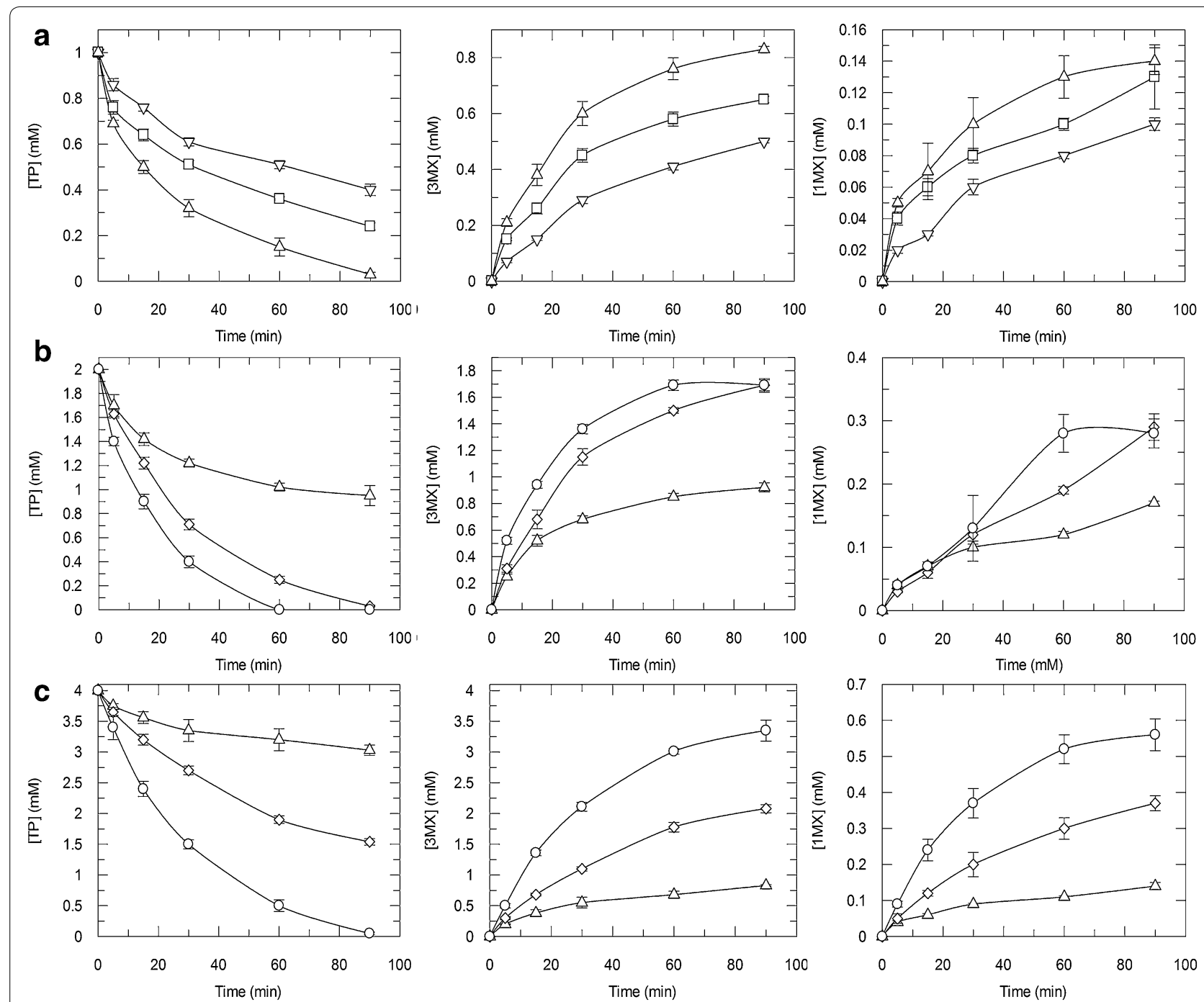

Fig. 4 Effect of cell and substrate concentrations on $3 \mathrm{MX}$ production by E. coli pDdA. Resting cell assays were performed using 5 (open triangle), 10 (open square), 15 (open triangle), 30 (open diamond), and 60 (open circle) mg/mL wet cells. TP concentrations were $1 \mathrm{mM}$ (a), $2 \mathrm{mM}(\mathbf{b})$, and $4 \mathrm{mM}$ (c). Concentrations of TP (left), 3MX (middle), and 1MX (right) are shown as means with standard deviations of triplicate reactions

of coffee and tea into Saccharomyces cerevisiae. The resulting strain produced a very low level $(0.38 \mathrm{mg} / \mathrm{L})$ of caffeine when fed exogenous xanthosine. Without addition of xanthosine, no caffeine was detected. Besides the low production level, use of plant genes restricts the possible products to 7-methylxanthine, theobromine, and caffeine, which are the metabolites of the caffeine biosynthetic pathway. Caffeine is mostly produced during the decaffeination of coffee beans $[52,53]$. Theobromine and TP are mostly produced synthetically $[54,55]$, although extraction from plants is possible [56]. Thus, further strain optimization and protein engineering will be required before use of plant-based genes can be used in a microbial system to produce high value methylxanthines.
Analytical characterization of biologically produced $3 \mathrm{MX}$

The purity of both $3 \mathrm{MX}$ and $1 \mathrm{MX}$ was analyzed by analytical HPLC using appropriate authentic standards. The retention time of the biologically produced products (Additional file 1: Figure S3) and authentic standards were identical. The High Resolution LC-MS spectrum of biologically produced and standard 3MX matched very well (Fig. 5) and corresponded to the published spectrum [57]. LC/MS was recorded on ESI positive mode; distinct $\mathrm{M}+1$ ion peak at $167.0569 \mathrm{~m} / \mathrm{z}$ was observed both in the standard (Fig. 5a) and the biologically produced 3MX (Fig. 5b).

The ${ }^{1} \mathrm{H}$ NMR spectrum of biologically produced and standard 3-methyl xanthine also matched very well 


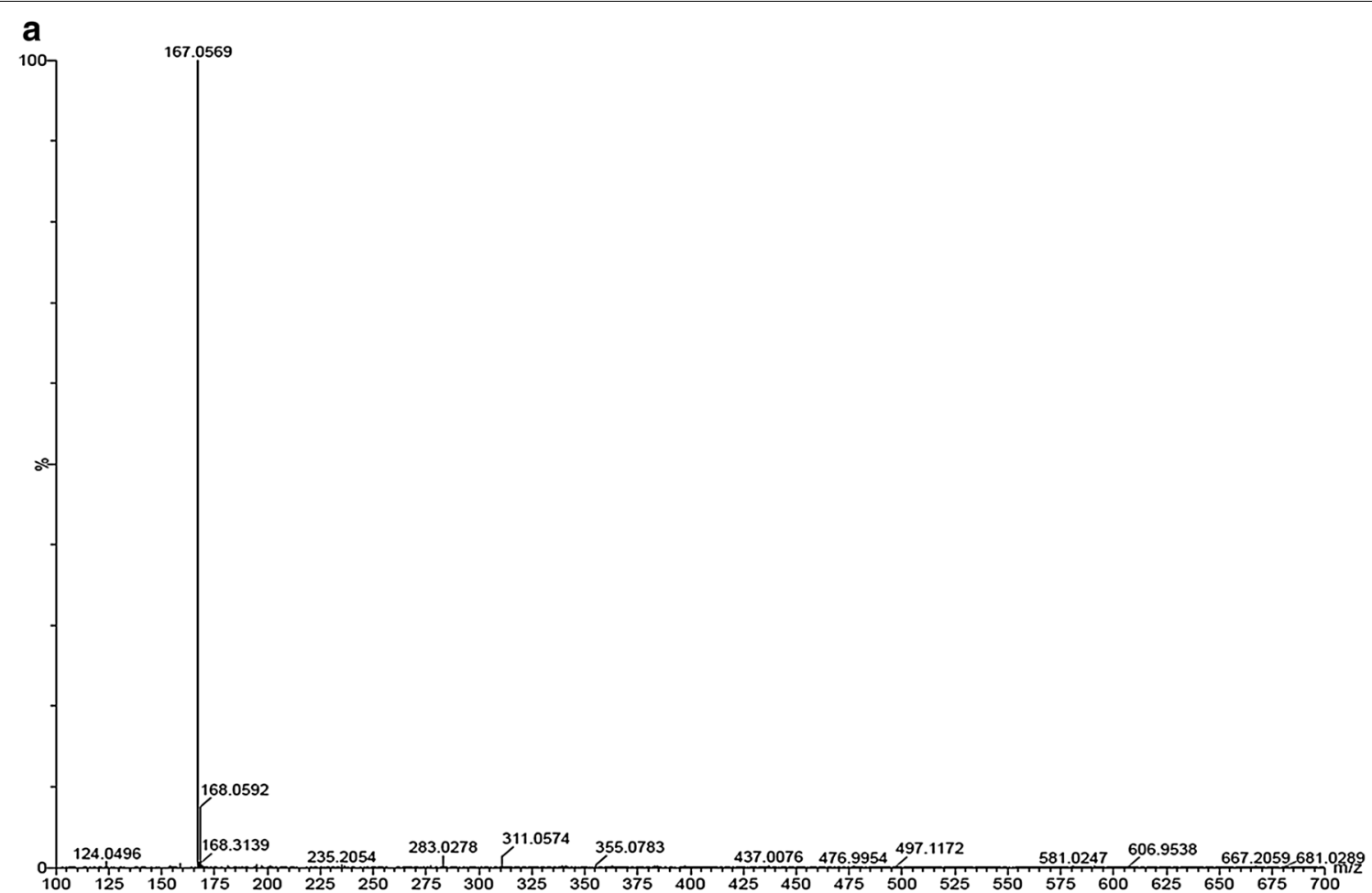

b

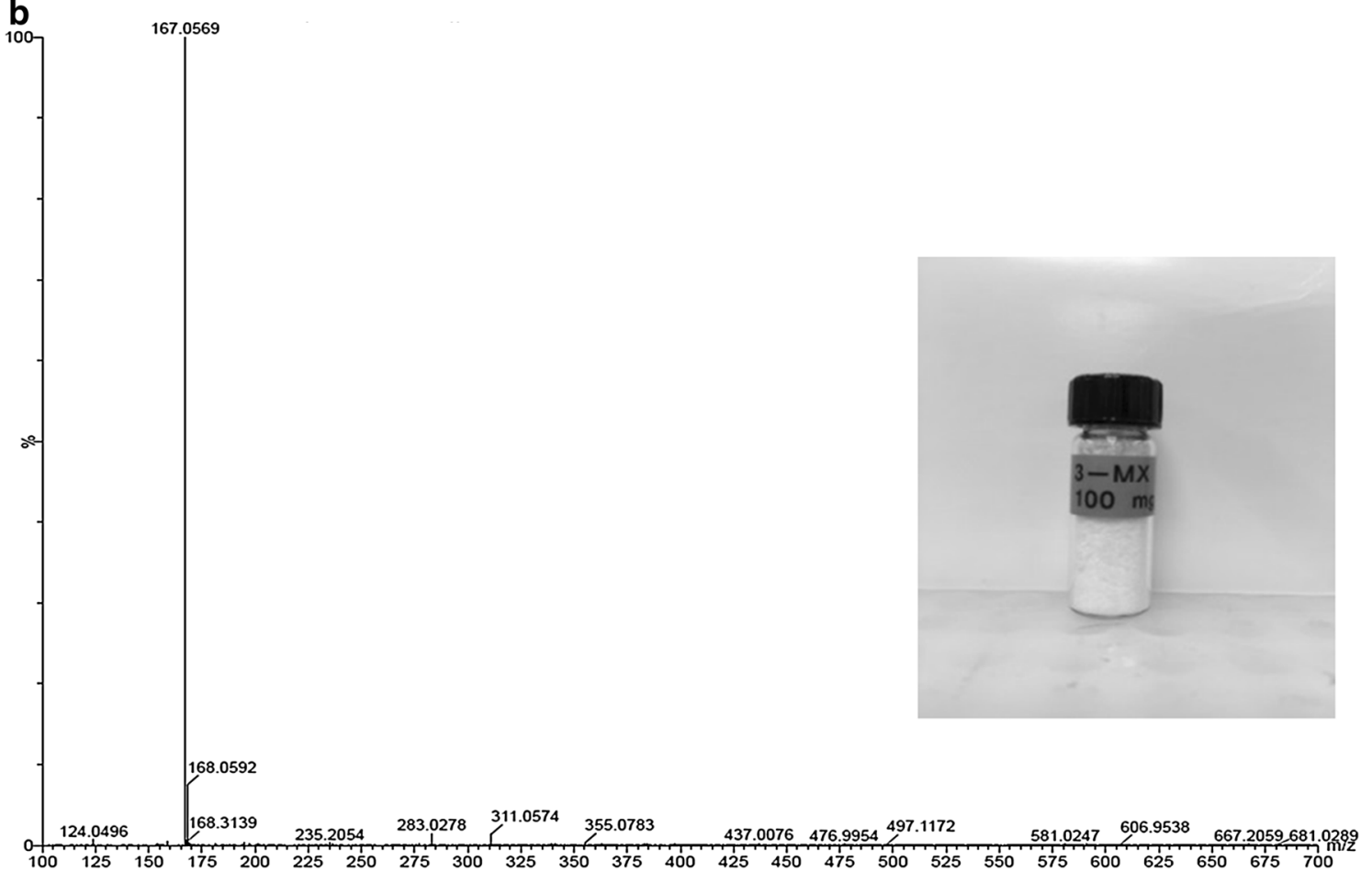

Fig. 5 LC-MS spectra of $3 M X$ samples. a Spectrum of $3 M X$ standard purchased from Sigma-Aldrich. $\mathbf{b}$ 3MX produced in this work. Inset to $\mathbf{b}$ : Purified, crystallized $3 \mathrm{MX}$ produced in this work 
(Additional file 1: Figure S4). ${ }^{1} \mathrm{H}$ NMR was recorded on a Bruker $500 \mathrm{MHz}$ spectrophotomer using DMSO- $\mathrm{d}_{6}$ as solvent. Standard 3-methylxantine showed presence of peaks at $\delta 13.48(\mathrm{~s}, 1 \mathrm{H})$ and $11.07(\mathrm{~s}, 1 \mathrm{H})$ corresponding to $-\mathrm{NH}$ proton, and peaks at $\delta 8.01$ and 3.3 corresponding to $-\mathrm{C}=\mathrm{H}(\mathrm{s}, 1 \mathrm{H})$ and $-\mathrm{CH}_{3}$ group $(\mathrm{s}, 3 \mathrm{H})$. The biologically produced 3MX also showed peaks at $\delta 13.48$ (s, $1 \mathrm{H})$ and $11.07(\mathrm{~s}, 1 \mathrm{H})$ corresponding to $-\mathrm{NH}$ proton, and peaks at $\delta 8.0$ and 3.3 corresponding to $-\mathrm{C}=\mathrm{H}(\mathrm{s}, 1 \mathrm{H})$ and $-\mathrm{CH}_{3}$ group $(\mathrm{s}, 3 \mathrm{H})$.

\section{Conclusions}

Our present work describes, for the first time, biocatalytic production of 3MX from TP with high yield. The process is carried out under ambient conditions in a single step using metabolically engineered $E$. coli. The larger vision of our work is to produce several high-value methylxanthines using specific combinations of $n d m$ genes metabolically engineered in $E$. coli while choosing the best feedstock to get the highest yield of the specific product. This represents a new biocatalytic platform for production of methylxanthines using multiple cheap feedstocks and a common process of fermentation to yield biocatalyst, reaction conditions, and separation process.

\section{Methods}

\section{Chemicals and reagents}

TP, $1 \mathrm{MX}, 3 \mathrm{MX}$, and xanthine were purchased from Sigma-Aldrich (St. Louis, MO). Luria-Bertani Lennox (LB) and Difco Select APS ${ }^{\mathrm{TM}}$ Super Broth (SB) dehydrated media were obtained from Becton-Dickinson and Company (Sparks, MD). Isopropyl $\beta$-D-thiogalactopyranoside (IPTG) was obtained from RPI Corp. (Mt. Prospect., IL). All PCR reactions were performed with Phusion HF polymerase from New England Biolabs (Ipswich, MA). Restriction enzymes and PCR reagents were also purchased from New England Biolabs. PCR primers were ordered from Integrated DNA Technologies (Coralville, IA). HPLC-grade methanol (J.T. Baker, Phillipsberg, NJ) was used in all chromatographic studies.

\section{Plasmid construction}

All plasmids and strains used in this work are listed in Table 1. The pACYCDuet-1 vector backbone, which has a low-to-medium copy number of 10-12, was used for plasmids dAA, dA, dDD, and dDA. Plasmid dA was created by adding a single copy of $n d m A$ in a manner that removed the second multiple cloning site. Plasmids pAD1 and pET28-His-ndmD contain the pET32a $(+)$ and pET28a $(+)$ vector backbones, respectively, which have a copy number of approximately 40. All genes are under the control of the strong $\mathrm{T} 7$ promoter for induction with IPTG. In the case of plasmid pAD1, the genes $n d m A$ and $n d m D$ are under the control of a single T7 promoter with a short synthetic ribosomal binding site between the two genes to promote translation of $n d m D$.

The $n d m A$ gene was amplified by PCR from $P$. putida CBB5 genomic DNA (gDNA) with three sets of primers: ndmA-F-NcoI (5'-GCAAGGTCCATGGAGCAG GCGATCATCAATGATGA-3') and ndmA-R-KpnI (5'-CCTCCGGGTACCTTATATGTAGCTCCTATCG CTT-3') produced insert 1 , ndmA-F-NcoI and ndmAR-BamHI (5'-CCTCCGGGATCCTTATATGTAGCTCC TATCGCTT-3') produced insert 2, and ndmA-F-NdeI (5'-GCACGGCATATGGAGCAGGCGATCATCAATG ATGA-3') and ndmA-R-KpnI produced insert 3. Insert 1 was cloned into the pACYCDuet- 1 plasmid at the NcoI and KpnI sites, resulting in plasmid dA. This plasmid contained only one copy of $n d m A$ controlled by the T7 promoter. Insert 2 was also cloned into the pACYCDuet-1 plasmid using the NcoI and BamHI sites, resulting in plasmid dA0. Plasmid dA0 contained one copy of $n d m A$ and a second, empty multiple cloning site. Insert 3 was cloned into the second multiple cloning site of plasmid dA0 at the NdeI and KpnI sites, resulting in plasmid dAA.

In a similar fashion, the $n d m D$ gene was also amplified from $P$. putida CBB5 gDNA by PCR using two sets of primers: ndmD-F-NcoI (5'-GTGAGATCCATGGACAA ACTTGACGTCAACCAGTGG-3') and ndmD-R-BamHI (5'-GGGACGGGGATCCTCACAGATCGAGAACG ATTTTTTTGGA-3') produced insert 4 , and ndmD-FNdeI (5'-GTGAGATCATATGAACAAACTTGACGTCA ACCAGTGG-3') and ndmD-R-KpnI (5'-GGGACGGGG TACCTCACAGATCGAGAACGATTTTTTTGGA-3') produced insert 5 . Insert 4 was cloned into the pACYCDuet-1 plasmid at the NcoI and BamHI sites, resulting in plasmid $\mathrm{dD} 0$, which contained one copy of $n d m D$ and a second, empty multiple cloning site. Insert 5 was cloned into the empty multiple cloning site at the NdeI and KpnI sites of $\mathrm{dD} 0$, resulting in plasmid $\mathrm{dDD}$. Insert 3 (containing $n d m A$ ) was also cloned into the NdeI and KpnI sites of $\mathrm{dD} 0$, yielding plasmid $\mathrm{dDA}$. DNA sequencing of all plasmids confirmed that PCR amplification and cloning procedures did not introduce any mutations into the gene sequences.

\section{Strain construction}

E. coli BL21(DE3) is the parent strain for all bacterial strains used. A list of all strains in this study is given in Table 1. Plasmids dDD, dDA, and dAA were transformed into strain $\mathrm{pAD} 1$, which already contained plasmid pAD1 [23], yielding strains pAD1dDD, pAD1dDA, and pAD1dAA, respectively. Plasmids dAA and dA were transformed into strain $\mathrm{pHisD}$, which already contained pET28-His-ndmD [43], resulting in strains pDdAA and $\mathrm{pDd} A$, respectively. Transformants were recovered on LB 
agar containing appropriate antibiotics at the following levels: $34 \mu \mathrm{g} / \mathrm{mL}$ chloramphenicol, $100 \mu \mathrm{g} / \mathrm{mL}$ ampicillin and $30 \mu \mathrm{g} / \mathrm{mL}$ kanamycin.

\section{Cell growth and protein expression}

E. coli strains were grown in SB or LB medium with appropriate antibiotic at $37^{\circ} \mathrm{C}$ with shaking at $250 \mathrm{rpm}$. Concentration of antibiotic used was 34,30 , and $100 \mu \mathrm{g} / \mathrm{mL}$ for chloramphenicol, kanamycin, and ampicillin respectively. Cell density was monitored by measuring the optical density at $600 \mathrm{~nm}\left(\mathrm{OD}_{600}\right)$. Upon reaching an $\mathrm{OD}_{600}$ of $\sim 0.5$, Ferric chloride $\left(\mathrm{FeCl}_{3} \cdot 6 \mathrm{H}_{2} \mathrm{O}\right)$ was added $(0.02 \mathrm{mM}$ final concentration) and temperature was lowered to $18{ }^{\circ} \mathrm{C}$. When the OD reached (0.8-1), IPTG was added $(0.2 \mathrm{mM}$ final concentration) to induce expression of $n d m A$ and $n d m D$. The IPTG concentration of $0.2 \mathrm{mM}$ was previously determined to give optimum protein expression [43]. Cells were harvested after (14-16) hours of induction by centrifugation at $10,000 \mathrm{~g}$ for $20 \mathrm{~min}$ at $4{ }^{\circ} \mathrm{C}$ and washed twice in $50 \mathrm{mM}$ cold potassium phosphate (KPi) buffer (pH 7.5). Pelleted cells (wet cells) were weighed and re-suspended in $50 \mathrm{mM}$ KPi buffer prior to activity assays.

\section{Assays for $3 \mathrm{MX}$ and $1 \mathrm{MX}$ production}

Other than where noted, reactions were carried out in $2 \mathrm{~mL}$ microcentrifuge tubes with $1 \mathrm{~mL}$ total reaction volume containing an initial TP concentration of $1 \mathrm{mM}$ and wet cell concentration of $15 \mathrm{mg} / \mathrm{mL}$. A VWR ${ }^{\circledR}$ symphony ${ }^{\mathrm{TM}}$ Incubating Microplate Shaker was used to carry out the reaction at $30{ }^{\circ} \mathrm{C}$ and $400 \mathrm{rpm} .100 \mu \mathrm{L}$ Samples were taken periodically for HPLC analysis, and concentrations of TP, $3 \mathrm{MX}$ and $1 \mathrm{MX}$ were calculated using appropriate standards. Reactions for product isolation were carried out in $1.3 \mathrm{~L}$ total volume with the same cell and TP concentrations as above ( $15 \mathrm{~g} / \mathrm{L}$ and $1 \mathrm{mM}$, respectively). These large-scale reactions were carried out in an Excella E24 Incubator Shaker (Eppendorf, Hamburg, Germany) shaker at $30^{\circ} \mathrm{C}$ and $250 \mathrm{rpm}$. After all TP was consumed, the post-reaction mixture was centrifuged at $10,000 \mathrm{x} g$ to separate the supernatant (products) from the cells.

\section{Preparatory HPLC methods and product isolation}

Purification of 3MX and 1MX was carried out with preparatory-scale HPLC using a Shimadzu LC-10AD HPLC system equipped with a photodiode array detector. A Hypersil BDS C18 column of $21.2 \mathrm{~mm}$ diameter and $25 \mathrm{~cm}$ length was used as the stationary phase. Methanol-wateracetic acid (5:95:0.5, vol/vol/vol) was used as the mobile phase with an optimized flow rate of $2.5 \mathrm{~mL} / \mathrm{min}$. The molecules resolved by the $\mathrm{C} 18$ column passed through the photodiode array detector, in which UV-visible absorption spectra were recorded. This HPLC is equipped with two pumps, A and B. The isocratic method was developed to be programmed so that pump B provided the mobile phase and pump A injected $25 \mathrm{~mL}$ of post-reaction mixture in $10 \mathrm{~min}$ periods. At the end of the preparative chromatography $900 \mathrm{~mL} 3 \mathrm{MX}$ solution and $700 \mathrm{~mL} 1 \mathrm{MX}$ solution were collected in two separate bottles. The solutions were concentrated by vacuum drying using Buchi Rotovap R114. The bath temperature was $60-70{ }^{\circ} \mathrm{C}$. Volume reduction was $200 \mathrm{~mL}$ for $3 \mathrm{MX}$ solution and $150 \mathrm{~mL}$ $1 \mathrm{MX}$. Both solutions were frozen to $-80^{\circ} \mathrm{C}$ and then were dried overnight in a Virtis Genesis 35EL freeze dryer (SP Scientific, Stone Ridge, NY) with a vacuum of 90 torr.

\section{Analytical procedures}

Identification and quantification of TP, 3MX, and 1MX were conducted on the same HPLC system described above. A Hypersil BDS C18 column (4.6 by $125 \mathrm{~mm}$ ) was used as the stationary phase. The same mobile phase was used with a flow rate of $0.5 \mathrm{~mL} / \mathrm{min}$. Purity of $3 \mathrm{MX}$ was confirmed by high resolution LC-MS facility at the University of Iowa, Department of Chemistry using a Waters Q-TOF Premier interfaced with an Acquity UPLC system. The NMR results were obtained from the NMR facility at the Chemistry Department of the University of Iowa. The spectrum was recorded in DMSO- $d_{6}$ with a Bruker DRX 500 NMR spectrometer at $300 \mathrm{~K}$. The chemical shifts were relative to DMSO- $d_{6}$ using the standard $\delta$ notation in parts per million.

\section{Additional file}

Additional file 1: Table S1. Prices of various natural methylxanthines obtained from the Sigma-Aldrich website on 18 September, 2015. Table S2. Estimated copy number of $n d m A$ and $n d m D$ genes in strains used in this study. Table $\mathbf{S 3}$. Comparison of growth and activity of resting cell suspensions of strains pDdA, pDdAA, and pAD1dDD. Concentrations of $\mathrm{TP}, 3 \mathrm{MX}$, and $1 \mathrm{MX}$ after $90 \mathrm{~min}$ are reported as means with standard deviations of triplicate reactions. Table S4. Comparison of growth and activity of resting cell suspension of strain pDdA grown in LB and SB. Concentrations of TP, $3 M X$, and $1 M X$ after $2 \mathrm{~h}$ are reported as means with standard deviations of triplicate reactions. Figure S1. Maps of plasmids in strains used to produce $3 \mathrm{MX}$ from TP. ori_pBR322, pBR322 origin of replication; ori_P15A, P15A origin of replication; Amp-R, ampicillin resistance gene, Kan- $R$, kanamycin resistance gene, CAT, chloramphenicol resistance gene, ndmA, N1-demethylase gene; ndmD, N-demethylase reductase gene; His-ndmD, N-terminal His6-tagged N-demethylase reductase gene; T7, T7 promoter. Plasmids beginning with " $p$ " use pET backbones, plasmids beginning with " $d$ " use the pACYCDuet-1 plasmid backbone. Figure S2. SDS-PAGE analysis of $n d m A$ and $n d m D$ expression in metabolically engineered strains of E. coli. A total of $10 \mu \mathrm{g}$ protein was loaded into each well. Molecular weights of markers (in $\mathrm{kDa}$ ) are shown to the left of the gel. Blue arrows indicate NdmA and NdmD protein bands. Lane 1, pAD1 soluble fraction; lane 2, pAD1 insoluble fraction; lane 3, pDdA soluble fraction; lane 4, pDdA insoluble fraction; lane 5, BL21(DE3) soluble fraction (negative control); lane 6, molecular weight standard; lane 7, pAD1DD soluble fraction; lane 8, pAD1DD insoluble fraction; lane 9, pDdAA soluble fraction; lane 10, pDdAA insoluble fraction. Figure S3. Separation of $3 \mathrm{MX}$ and $1 \mathrm{MX}$ by preparative chromatography. Retention times of $3 \mathrm{MX}$ and $1 \mathrm{MX}$ are 116 and $135 \mathrm{~min}$, respectively. Figure S4. NMR of 3-methylxanthine. (A) NMR of $3 M X$ standard obtained from Sigma Aldrich. (B) NMR of biologically produced and purified $3 \mathrm{MX}$ sample produced in this work 


\section{Abbreviations}

TP: theophylline; 1MX: 1-methylxanthine; 3MX: 3-methylxanthine; LB: LuriaBertani broth; SB: super broth; HPLC: high pressure liquid chromatography; LC-MS: liquid chromatography-mass spectrophotometry; NMR: nuclear magnetic resonance; SDS-PAGE: sodium dodecyl sulfate-polyacrylamide gel electrophoresis.

\section{Authors' contributions}

KA carried out cell growth, biotransformation reactions, chemical purifications, participated in study design, and drafted the manuscript. RS performed all molecular biology work and initial strain screening, participated in study design, and drafted the manuscript. SG participated in the design of the study and data analysis. MS conceived the study, participated in its design, coordination, and data analysis, and helped in the finalization of the manuscript. All authors read and approved the final manuscript.

\section{Author details}

${ }^{1}$ Department of Chemical and Biochemical Engineering, The University of lowa, Coralville, IA 52241, USA. ${ }^{2}$ Department of Chemical and Biological Engineering, The University of Alabama, Tuscaloosa, AL 35487, USA. ${ }^{3}$ Center for Biocatalysis and Bioprocessing, University of lowa Research Park, The University of lowa, 2501 Crosspark Road-Suite C100, Coralville, IA 52241, USA.

${ }^{4}$ Department of Chemical Engineering, University of Baghdad, Baghdad, Iraq

\section{Acknowledgements}

Funding for this work was provided by University of lowa startup funds.

\section{Competing interests}

The authors declare that they have no competing interests.

Received: 5 December 2015 Accepted: 10 December 2015 Published online: 21 December 2015

\section{References}

1. Ashihara $\mathrm{H}, \mathrm{Crozier} \mathrm{A}$. Biosynthesis and metabolism of caffeine and related purine alkaloids in plants. Adv Bot Res. 1999;47:3425-31.

2. Anaya AL, Cruz-Ortega R, Waller GR. Metabolism and ecology of purine alkaloids. Front Biosci. 2006;11:2354-70.

3. Dash SS, Gummadi SN. Catabolic pathways and biotechnological applications of microbial caffeine degradation. Biotechnol Lett. 2006;28:1993-2002

4. Lelo A, Miners J, Robson R, Birkett D. Quantitative assessment of caffeine partial clearances in man. Br J Clin Pharmacol. 1986;22:183-6.

5. Daly J. Caffeine analogs: biomedical impact. Cell Mol Life Sci. 2007;64:2153-69.

6. Daly JW, Butts-Lamb P, Padgett W. Subclasses of adenosine receptors in the central nervous system: interaction with caffeine and related methylxanthines. Cell Mol Neurobiol. 1983;3:69-80.

7. Jacobson KA, Van Galen PJ, Williams M. Adenosine receptors: pharmacology, structure-activity relationships, and therapeutic potential. J Med Chem. 1992;35:407-22.

8. Chasin M, Harris D. Inhibitory and activators of cyclic nucleotide phosphodiesterase. Adv Cyclic Nucleotide Res. 1976;7:225.

9. Butcher R, Sutherland EW. Adenosine $3^{\prime}, 5^{\prime}$-phosphate in biological materials. I. Purification and properties of cyclic $3^{\prime}, 5^{\prime}$-nucleotide phosphodiesterase and use of this enzyme to characterize adenosine $3^{\prime}, 5^{\prime}$-phosphate in human urine. J Biol Chem. 1962;237:1244.

10. Bianchi $C$. The effect of caffeine on radiocalcium movement in frog sartorius. J Gen Physiol. 1961;44:845-58.

11. Frank G. Utilization of bound calcium in the action of caffeine and certain multivalent cations on skeletal muscle. J Physiol. 1962;163:254-68.

12. Daly JW. Alkylxanthines as research tools. J Auton Nerv Syst. 2000;81:44-52.

13. Shi D, Padgett WL, Daly JW. Caffeine analogs: effects on ryanodine-sensitive calcium-release channels and GABAA receptors. Cell Mol Neurobiol. 2003;23:331-47.
14. Marangos P, Paul SM, Parma A, Goodwin F, Syapin P, Skolnick P. Purinergic inhibition of diazepam binding to rat brain (in vitro). Life Sci. 1979;24:851-7.

15. Williams JF, Lowitt S, Polson JB, Szentivanyi A. Pharmacological and biochemical activities of some monomethylxanthine and methyluric acid derivatives of theophylline and caffeine. Biochem Pharmacol. 1978;27:1545-50.

16. Birkett D, Dahlqvist R, Miners J, Lelo A, Billing B. Comparison of theophylline and theobromine metabolism in man. Drug Metab Disposition. 1985;13:725-8.

17. Lee SW, Zhao L, Pardi A, Xia T. Ultrafast dynamics show that the theophylline and 3-methylxanthine aptamers employ a conformational capture mechanism for binding their ligands. Biochemistry. 2010;49:2943-51.

18. Desai SK, Gallivan JP. Genetic screens and selections for small molecules based on a synthetic riboswitch that activates protein translation. J Am Chem Soc. 2004;126:13247-54.

19. Tang-Liu D, Williams R, Riegelman S. Disposition of caffeine and its metabolites in man. J Pharmacol Exp Ther. 1983;224:180-5.

20. Scott N, Chakraborty J, Marks V. Urinary metabolites of caffeine in pregnant women. Br J Clin Pharmacol. 1986:22:475-8.

21. Birkett D, Miners J, Day R. 1-Methylxanthine derived from theophylline as an in vivo biochemical probe of allopurinol effect. Br J Clin Pharmacol. 1991;32:238.

22. Birkett DJ, Miners JO, Valente L, Lillywhite K, Day R. 1-Methylxanthine derived from caffeine as a pharmacodynamic probe of oxypurinol effect. Br J Clin Pharmacol. 1997:43:197-200.

23. Summers RM, Mohanty SK, Gopishetty S, Subramanian M. Genetic characterization of caffeine degradation by bacteria and its potential applications. Microb Biotechnol. 2015;8:369-78.

24. Taylor EC, Barton JW, Paudler WW. Studies in purine chemistry. X. Some derivatives of 9-aminopurines. J Org Chem. 1961;26:4961-7.

25. Shamim MT, Ukena D, Padgett WL, Daly JW. Effects of 8-phenyl and 8-cycloalkyl substituents on the activity of mono-, di, and trisubstituted alkylxanthines with substitution at the 1-, 3-, and 7-positions. J Med Chem. 1989:32:1231-7.

26. Gopishetty S, Louie T, Yu C, Subramanian M. Microbial degradation of caffeine, methylxanthines, and its biotechnological applications. In: Thatoi $\mathrm{H}$, Mishra B, editors. Microbial biotechnology methods and applications. New Delhi: Narosa Publishing Houst Pvt, Ltd; 2011. p. 44-67.

27. Traube W. Der synthetische aufbau der harnsäure, des xanthins, theobromins, theophyllins und caffeïns aus der cyanessigsäure. Ber Dtsch Chem Ges. 1900;33:3035-56

28. Yoneda F, Higuchi M, Mori K, Senga K, Kanamori Y, Shimizu K, Nishigaki S. Synthesis of xanthines by dehydrogenative cyclization of 6-amino5-benzylideneaminouracils with diethyl azodicarboxylate. Chem Pharm Bull (Tokyo). 1978;26:2905-10.

29. Lister JH. The chemistry of heterocyclic compounds, The Purines: Supplement 1. Wiley-Interscience; 2009

30. Zavialov IA, Dahanukar VH, Nguyen H, Orr C, Andrews DR. New and Practical Method for Synthesis of 1-and 1, 3-Substituted Xanthines. Org Lett. 2004:6:2237-40

31. Allwood MB, Cannan B, van Aalten DMF, Eggleston IM. Efficient synthesis of 1, 3, 7-substituted xanthines by a safety-catch protection strategy. Tetrahedron. 2007;63:12294-302.

32. Liu G, Reddy PSMM, Barber JR, Ng SC, Zhou Y. Synthesis of Novel 3, 7-Dihydro-purine-2, 6-dione Derivatives. Synth Commun. 2010;40:1418-36.

33. Hollingsworth RG, Armstrong JW, Campbell E. Pest control: caffeine as a repellent for slugs and snails. Nature. 2002;417:915-6.

34. Nathanson JA. Caffeine and related methylxanthines: possible naturally occurring pesticides. Science. 1984;226:184-7.

35. Dash SS, Gummadi SN. Biodegradation of caffeine by Pseudomonas sp. NCIM 5235. Res J Microbiol. 2010;5:745-53.

36. Gokulakrishnan S, Chandraraj K, Gummadi SN. A preliminary study of caffeine degradation by Pseudomonas sp. GSC 1182. Int J Food Microbiol. 2007:113:346-50

37. Yu CL, Kale Y, Gopishetty S, Louie TM, Subramanian M. A novel caffeine dehydrogenase in Pseudomonas sp. strain CBB1 oxidizes caffeine to trimethyluric acid. J Bacteriol. 2008;190:772-6. 
38. Yu CL, Louie TM, Summers R, Kale Y, Gopishetty S, Subramanian M. Two distinct pathways for metabolism of theophylline and caffeine are coexpressed in Pseudomonas putida CBB5. J Bacteriol. 2009;191:4624-32.

39. Yu CL, Summers RM, Li Y, Mohanty SK, Subramanian M, Pope RM. Rapid identification and quantitative validation of a caffeine-degrading pathway in Pseudomonas sp. CES. J Proteome Res. 2014;14:95-106.

40. Mazzafera P, Olsson O, Sandberg G. Degradation of caffeine and related methylxanthines bySerratia marcescens isolated from soil under coffee cultivation. Microb Ecol. 1996;31:199-207.

41. Woolfolk C. Metabolism of N-methylpurines by a Pseudomonas putida strain isolated by enrichment on caffeine as the sole source of carbon and nitrogen. J Bacteriol. 1975;123:1088-106.

42. Madyastha K, Sridhar G. A novel pathway for the metabolism of caffeine by a mixed culture consortium. Biochem Biophys Res Commun. 1998;249:178-81.

43. Summers RM, Louie TM, Yu C-L, Gakhar L, Louie KC, Subramanian M. Novel, highly specific N-demethylases enable bacteria to live on caffeine and related purine alkaloids. J Bacteriol. 2012;194:2041-9.

44. Summers R, Gopishetty S, Mohanty S, Subramanian M. New genetic insights to consider coffee waste as feedstock for fuel, feed, and chemicals. Cent Eur J Chem. 2014;12:1271-9.

45. BuyersGuideChem. http://www.buyersguidechem.com/AliefAus. php?pnumm =530921731638. Accessed 28 Oct 2015.

46. Summers RM, Seffernick JL, Quandt EM, Yu CL, Barrick JE, Subramanian MV. Caffeine junkie: an unprecedented glutathione S-transferasedependent oxygenase required for caffeine degradation by Pseudomonas putida CBB5. J Bacteriol. 2013;195:3933-9.
47. Lee Y-L, Su M-S, Huang T-H, Shaw J-F. C-terminal His-tagging results in substrate specificity changes of the thioesterase I from Escherichia coli. J Am Oil Chem Soc. 1999;76:1113-8.

48. Hakil M, Denis S, Viniegra-Gonzalez G, Augur C. Degradation and product analysis of caffeine and related dimethylxanthines by filamentous fungi. Enzyme Microb Technol. 1998;22:355-9.

49. Asano Y, Komeda T, Yamada H. Microbial production of theobromine from caffeine. Biosci Biotechnol Biochem. 1993;57:1286-9.

50. Dash SS, Gummadi SN. Degradation kinetics of caffeine and related methylxanthines by induced cells of Pseudomonas sp. Curr Microbiol. 2007;55:56-60.

51. Jin L, Bhuiya MW, Li M, Liu X, Han J et al. Metabolic engineering of Saccharomyces cerevisiae for caffeine and theobromine production. PLoS One. 2014;9(8):e105368. doi:10.1371/journal.pone.0105368

52. Udayasankar K, Manohar B, Chakkalingam A. A note on supercritical carbon dioxide decaffeination of coffee. J Food Sci Technol. 1986;23:326-8.

53. Ramalakshmi K, Raghavan B. Caffeine in coffee: its removal. Why and how? Crit Rev Food Sci Nutr. 1999;39:441-56.

54. Bobranski B, Synowiedski Z. New syntheses of caffeine and theophylline. J Am Pharm Assoc. 1948;37:62-4.

55. Hu X, Wan X, Bal R, Yang H. Theobromine and caffeine recovery with solvent extraction. Sep Sci Technol. 2003:38:3609-24.

56. Saldaña MD, Mohamed RS, Baer MG, Mazzafera P. Extraction of purine alkaloids from mate (llex paraguariensis) using supercritical $\mathrm{CO}_{2}$. J Agric Food Chem. 1999;47:3804-8.

57. Human metabolome database 3-methylxanthine spectrum. http://www. hmdb.ca/spectra/ms_ms/5549. Accessed 12 Nov 2015.

\section{Submit your next manuscript to BioMed Central and we will help you at every step:}

- We accept pre-submission inquiries

- Our selector tool helps you to find the most relevant journal

- We provide round the clock customer support

- Convenient online submission

- Thorough peer review

- Inclusion in PubMed and all major indexing services

- Maximum visibility for your research

Submit your manuscript at www.biomedcentral.com/submit

\section{(O) Biomed Central}

